\title{
Anaesthetic management of an infant for Achilles tendon lengthening by combined intrathecal and ultrasound guided sciatic nerve blocks
}

\author{
S Parthasarathy ${ }^{I^{*}}$, Surya Ratnasamy ${ }^{2}$ \\ Associate Professor ${ }^{*}$, Postgraduate student ${ }^{2}$, Mahatma Gandhi Medical college and Research Institute \\ Puducherry, India.
}

\begin{abstract}
A four-month old, $4.5 \mathrm{~kg}$ weight infant with normal mentation was posted for Achilles tendon lengthening for bilateral club foot. Anaesthesia was provided with intrathecal administration of $0.4 \mathrm{ml}$ of $0.5 \%$ bupivacaine and popliteal sciatic nerve block with $0.2 \%$ bupivacaine $1.5 \mathrm{ml}$ to each side. The sciatic nerve was looking hypoechoic than the classical honeycomb possibly due to lesser development of connective tissue. The infant had satisfactory analgesia for $12 \mathrm{hrs}$ post-surgery and there was no analgesic requirement. Routine follow up for three months was uneventful. We conclude that intrathecal bupivacaine supplemented with ultrasound guided peripheral nerve blocks can be administered even in infants. As case reports like this are rare to find in literature, we report this case for its uniqueness.
\end{abstract}

Keywords: anaesthesia; infant; intrathecal; ultrasound; nerve block; sciatic nerve

\section{Introduction}

Paediatric spinal anaesthesia is not only a safe alternative to general anaesthesia but often can be the anaesthetic technique of choice in many lower abdominal and lower limb surgeries in children including infants. ${ }^{1}$ Peripheral nerve blocks in children have been considered challenging due to need for targeting neural structures which often course very close to critical structures and the need for limiting the volume of local anaesthetic solution below toxic levels. Real-time ultrasound imaging improves the ability of the anaesthesiologist to identify the neural elements, place the needle in close proximity to the target and precisely administer optimal volumes of the local anaesthetic. ${ }^{2}$ We present, a successful management of an infant for lower limb surgery with combined intrathecal and ultrasound guided sciatic nerve block.

*Correspondence: S Parthasarathy

E mail: painfreepartha@yahoo.com

iD https://orcid.org/0000-0002-3808-6722

Received: 06/08/2017

Accepted: 06/10/2017

DOI: http://doi.org/10.4038/slja.v26i1.8268

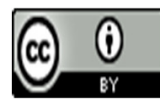

\section{Case history}

A 4-month-old male infant weighing $4.5 \mathrm{~kg}$ was admitted with bilateral club foot since birth. There was no history suggestive of any respiratory infection, other congenital abnormalities or a developmental delay. The baby was exclusively breast fed. On examination, the infant was awake, alert, moving all four limbs, afebrile with a heart rate of $110 / \mathrm{min}$. The cardiac, respiratory and nervous system examination were within normal limits. Bilateral Achilles tendon lengthening was planned. Investigations including haemoglobin (11gms\%), bleeding time, clotting time and blood grouping were done as a routine. On the day of surgery, following $4 \mathrm{hrsfasting}$ for breast feeds, standard monitors were connected and a baseline heart rate of $110 / \mathrm{min}$ was recorded. The patient was premedicated with atropine $100 \mathrm{mcg}$, midazolam $0.25 \mathrm{mg}$ and pentazocine $1.5 \mathrm{mg}$ i.v. for procedural sedation. Under aseptic precautions subarachnoid bock was performed with $25 \mathrm{G}$ Quincke spinal needle and $0.4 \mathrm{ml}$ of $0.5 \%$ hyperbaric bupivacaine was administered at L3 L4 level. Sensory blockade level of T10 was achieved. Calmness was achieved with nipple. (Figure 1)

Intraoperatively the infant received $30 \mathrm{ml}$ of crystalloids and maintained stable haemodynamics. 


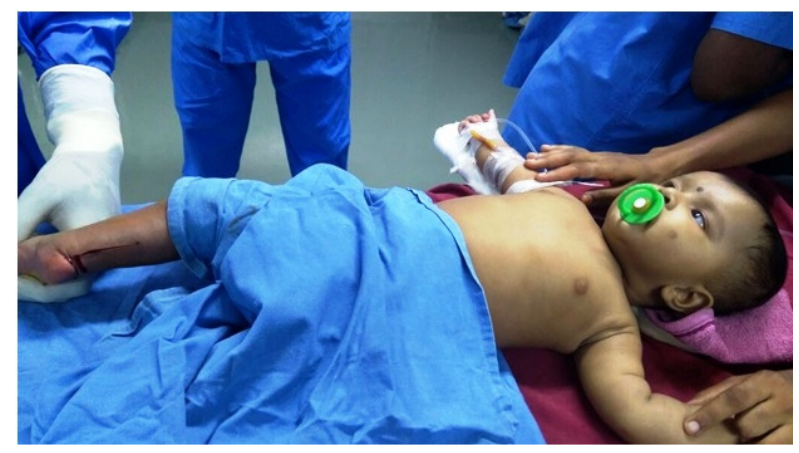

Figure 1

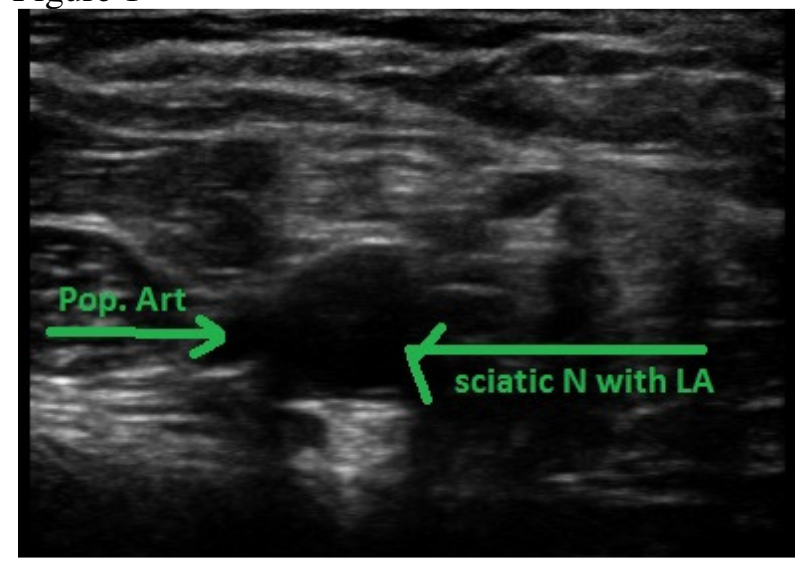

Figure 2

The infant was conscious and maintaining airway throughout the surgical period of one hour. Postoperatively under USG guidance (sonosite one inch HFL probe - 19-5) sciatic nerve block was given by popliteal approach with $0.2 \%$ bupivacaine, $1.5 \mathrm{ml}$ on each side for post-operative analgesia (Figure 2). Pain assessment was done using FLACC scoring system sequentially in the postoperative ward. FLACC score (Face, Legs, Activity, Cry, Consolability scale) was $0 / 10$ for $12 \mathrm{hrs}$ postsurgery. Paracetamol suppository was prescribed after twelve hours. The child was followed up for a period of three months and found to have no further complications.

\section{Discussion}

Intrathecal anaesthesia has its own advantages of reliable intense anaesthesia with less airway complications especially in infants. We used intra thecal anaesthesia to circumvent the possible airway and respiratory complications of general anesthesia. Other than the sedative drugs used by us, inhalational agents and ketamine have been used for procedural sedation. ${ }^{3}$ It has been described that the sciatic nerve usually divides distally in infants which was advantageous in our case to achieve complete block. The volume of local anaesthetic recommended for sciatic nerve block is $0.3 \mathrm{ml} / \mathrm{kg}$., Marinella Astuto $^{6}$ et al reported a case of fivemonth-old, $5 \mathrm{~kg}$ male infant with Goldenhar syndrome successfully treated with general anaesthesia with laryngeal mask airway and nerve stimulator guided sciatic nerve block in popliteal fossa for club foot surgery. They concluded that peripheral nerve block provided more comfortable emergence reducing anaesthetic depth and airway instrumentation with satisfactory post-operative analgesia. In their case, CRIES score was 2 at the arrival in the Post Anesthesia Care Unit, 1 at 15 and at 30 mins after surgery. In contrast, in our case we observed a FLACC scale of 0/10 up to $12 \mathrm{hrs}$ postsurgery. As the spinal anaesthetic technique is generally not expected to last for more than one hour, the comfort of the patient is definitely due to the block. In infants, we could image the sciatic nerve as a more hypoechoic structure than the classic honey combing appearance. This could be possibly due to less connective tissue development in infants. ${ }^{7}$ Hence we should be careful in visualizing the nerve especially near hypoechoic vessels. This assumes significance where nerve stimulation as a guide is impossible as was in our case. References for these possible mechanisms were not found and hence we suggest a comparative population based study of sonoanatomy among infants and adults in future.

\section{Conclusion}

We have presented successful management of club foot surgery in an infant with intrathecal bupivacaine followed by supplemental ultrasound guided popliteal sciatic nerve block. We found the sciatic nerve to be more hypoechoic in ultrasound and we postulate that this could be due to limited connective tissue. As such, due to close proximity to vessels and without honey combing, popliteal sciatic nerve block should be administered with extreme caution and vigilance.

\section{References}

1. Verma D, Naithani U, Gokula C, Harsha. Spinal anesthesia in infants and children: A one year prospective audit. Anesth Essays Res 2014;8(3):324-9. 
2. Tsui BCH, Suresh S. Ultrasound Imaging for Regional Anesthesia in Infants, Children, and Adolescents: Review of Current Literature and Its Application in the Practice of Extremity and Trunk Blocks. Anesthesiology 2010;112(2): 473-492 https://doi.org/10.1097/ALN.0b013e3181c5dfd7 PMid:20068455

3. Mahajan C, Dash HH. Procedural sedation and analgesia in pediatric patients. Journal of Pediatric Neurosciences. 2014;9(1):1-6.

https://doi.org/10.4103/1817-1745.131469

PMid:24891893 PMCid:PMC4040023

4. Ivani G, Tonetti F. Postoperative analgesia in infants and children: new developments. Minerva Anestesiol. 2004;70(5):399-403.

PMid:15181422

5. Reinoso-Barbero F, Saavedra B, Segura-Grau E, Llamas A. Anatomical comparison of sciatic nerves between adults and newborns: clinical implications for ultrasound guided block. Journal of Anatomy. 2014;224(2):108-112. https://doi.org/10.1111/joa.12128 PMid:24433381 PMCid:PMC3969055

6. Astuto M, Privitera C, Gurrieri C, et al. Sciatic Nerve Block in the Popliteal Fossa Using Lateral Approach in an Infant with Goldenhar Syndrome. The Open Anesthesiology Journal, 2013;7: 12-14

7. Campbell EO, Samlan RA, McMullen NT, et al. Developmental changes in the connective tissues of the porcine recurrent laryngeal nerve. Journal of Anatomy. 2013;222(6):625-633.

https://doi.org/10.1111/joa.12046

PMid:23590663 PMCid:PMC3660414 